\title{
Population dynamics of citrus whitefly, Dialeurodes citri (Ashmead) on Citrus reticulate (Mandarin) var. Kinnow as influenced by weather conditions
}

\author{
T. Saini, Maha Singh Jaglan, S.S. Yadav , P. Jakhar and Rajbir Garg \\ Department of Entomology, CCS Haryana Agricultural University, Hisar-125004 (Haryana), INDIA \\ *Corresponding author. E-mail: tsaini398@gmail.com
}

Received: November 14, 2015; Revised received: May 19, 2016; Accepted: August 02, 2016

\begin{abstract}
A field study on population dynamics of citrus whitefly, Dialeurodes citri (Ashmead) on citrus mandarin (var. Kinnow) was carried out during 2014-15 at Centre of Excellence (COE) for Fruits situated in village Mangiana of district Sirsa, Haryana. The population of nymphs and adults of this pest was recorded from March 2014 to February 2015 at weekly interval. The nymphal population of the pest was observed only between $12^{\text {th }}$ to $47^{\text {th }}$ meteorological standard weeks (SW) with two major peaks i.e. one during $16^{\text {th }}$ SW with a population of 83.44 nymphs/ 20 leaves and the second during $40^{\text {th }} \mathrm{SW}$ with a population of 133.22 nymphs/20 leaves. The above said population dynamics confirmed that this pest remained inactive in pupal stage during winter i.e. $48^{\text {th }}$ to $11^{\text {th }} \mathrm{SW}$. Similar trend was observed in respect of adult population. Nymphal population showed significant positive correlation with morning relative humidity $(r=0.329)$ and sunshine hours $(r=0.362)$, while adult population was found to have positive correlation with sunshine hours only $(r=0.332)$. Multiple regression analysis of the pest population with environment variables indicated that out of 45 per cent variability in nymphal population, 37 per cent was due to relative humidity and sunshine hours. Out of the total variability of 30 per cent variation in adult population, 20 per cent was due to evening relative humidity, while 10 per cent attributed to sunshine hours. The other weather parameters were found to have no significant correlation with the pest population. Although study of population dynamics of this study were conducted elsewhere but this is first study of its kind in the state of Haryana. The population dynamics revealed by this study have far reaching significance in pest management strategy as integrated control measures may be focused only during the period wherein population exceeds economic threshold level (ETL). The information on population dynamics of any insect pest in a given ecological niche should be considered as starting point for evolving eco - friendly pest management package.
\end{abstract}

Keywords: Citrus, Dialeurodes citri, Kinnow, Population dynamics, Weather conditions

\section{INTRODUCTION}

Citrus (Rutaceae: Geraniales) fruits have the place of prides among the fruit crops grown in India and rank third after mango and banana. Among the various citrus fruits, Lime, lemons, sweet oranges and mandarin cover major area and are mainly grown in the state of Maharashtra, Andhra Pradesh, Karnataka, Odissa, Madhya Pradesh, Punjab and Haryana. In India, the citrus fruits occupy an area of 1042 (000'ha) with production of 10090 (000'MT) (Anonymous, 2013). The corresponding figures for the state of Haryana are 18.8 (000'ha) and 225.1 (000'MT), respectively (Anonymous, 2013).In Haryana, the major citrus growing districts are Sirsa, Hisar, Bhiwani, Gurgaon and Fatehabad.

Citrus plants are infested by large number of insectspests causing heavy yield penalty and even the qualitative loss becomes apparent. The proper management of any insect pest requires precise knowledge of its population dynamics and summary of all such factors which predispose the plant for its infestation. It was in this endeavour that the population dynamics of whitefly, Dialeurodes citri Ashmead (Hemiptera: Aleyrodidae) were studied with likely correlation between the population variability and variations in various weather parameters at the given point of time as the different workers have attributed outbreaks of this pest to favourable weather factors. This insect was specifically selected for the present study as being the serious pest of citrus plants. This insect is a sucking pest and cause damage to citrus fruits by removing significant amount of phloem sap resulting in reduced plant vigour and yield. Secretion of honeydew by this pest results in development of sooty mould growth on fruits causing further loss to the growers in terms of quality deterioration and comparatively low market price (Dhiman and Batra, 1998; Dhiman et al., 2000). The information on population dynamics of any insect pest in a given ecological niche should be considered as starting point for evolving eco- friendly pest management package. It is an established fact that population dynamics of any insect is greatly influenced by weather fluctuations and thereby the location specific studies become more imperative. It was with this in mind that the present study was carried out to investigate population dynamics of citrus whitefly, Dialeurodes citri 
(Ashmead) on citrus mandarin (var. Kinnow) as influenced by weather conditions.

\section{MATERIALS AND METHODS}

This study pertaining to population dynamics of citrus whitefly, Dialeurodes citri (Ashmead) was carried out during 2014-15 at Centre of Excellence (COE) for Fruits situated in village Mangiana of district Sirsa, Haryana. The host plants selected for the present study were five year old citrus (Citrus reticulate) plants i.e. Kinnow (var.) mandarin hybrid with root stock as rough lemon and being planted on ridges with spacing $6 \mathrm{~m} \times 4 \mathrm{~m}$. The population of nymphs and adults of D.citri was recorded from March 2014 to February 2015 at weekly interval from three plants in three replications by observing 20 random leaves per plant with the help of a hand lens (10X). The plants were kept completely free from insecticidal spray to enable the natural build up of population and allowing the limitation imposed by natural enemies. During each week, observations were recorded before 10:00 am having regard to comparative immobility of this insect in the morning hours. The population so recorded of both nymphs and adults were averaged and expressed as number of nymphs or adults per 20 leaves.

Data on weather parameter such as temperature, relative humidity, sunshine hours and rainfall was obtained from meteorological observatory of Central Institute of Cotton Research (CICR), Sirsa, Haryana. Correlations and regression analysis between the D.citri populations at different observation periods with different meteorological parameters were worked out using SPSS 16.0 version. The results have been discussed and interpreted in relation to the likely impact of weather parameters.

\section{RESULTS AND DISCUSSION}

Population dynamics: The Nymphal population of the pest was observed on the experimental plants only between $12^{\text {th }}$ to $47^{\text {th }}$ meteorological standard weeks (SW) with two major peaks i.e. one during $16^{\text {th }} \mathrm{SW}$ with a population of 83.44 nymphs/ 20 leaves and the second during $40^{\text {th }} \mathrm{SW}$ with a population of 133.22 nymphs/20 leaves. The population remained below 25.11 nymphs/20 leaves during the $22^{\text {nd }}$ to $31^{\text {st }} \mathrm{SW}$. On the other hand, quit high population, ranging from
55.89 to 83.44 nymphs/20 leaves was observed during $15^{\text {th }}$ to $18^{\text {th }} \mathrm{SW}$ and again from 87.22 to 133.22 nymphs/20 leaves during $36^{\text {th }}$ to $42^{\text {th }} \mathrm{SW}$. The above said population dynamics confirmed that this pest remained inactive in pupal stage during winter i.e. $48^{\text {th }}$ to $11^{\text {th }} \mathrm{SW}$ (Figs. 1-3).Almost similar trend was observed with respect to adult population. The adult population of whitefly remained quite high during $14^{\text {th }}$ to $18^{\text {th }} \mathrm{SW}$ (62.67 to 69.89 adults/20 leaves) and again during $35^{\text {th }}$ to $41^{\text {st }} \mathrm{SW}$ (43.22 to 76.67 adults/20 leaves). The lowest population of adults (i.e. $<20.78 / 20$ leaves) was observed between $20^{\text {th }}$ and $31^{\text {st }} \mathrm{SW}$. There was no adult population after $47^{\text {th }} \mathrm{SW}$ till $11^{\text {th }} \mathrm{SW}$ of the proceeding year (Figs. 4-5).

These results are in line with the findings of Sidhu and Batra (1992) and Batra et al.(2000) who also reported that $D$. citri population remains active from March to November in Punjab and that the pest had two peaks of population (first in the March-April and second in September-October). Argov et al. (1999) also reported that citrus whitefly entered diapause with shortening of days and decrease in temperature, and diapause occurring in the fourth instar was facultative, induced by shortening of day. Kumar (2001) also observed that $D$. citri population had two peaks i.e. first in March-April (30.75-47.50 nymphs/25 leaves) and second in September-October (78.50-92.75 nymphs/25 leaves).

Similar trend in population dynamics of this pest were reported by Sidhu and Batra, 1992; Batra et al., 2000; Argov et al., 1999 and Kumar, 2001.

Impact of weather on pest activity: Significant positive correlation was observed between the nymphal population of this pest and weather parameters namely morning relative humidity (RHm) and sunshine (SS) (r $=0.329$ and $\mathrm{r}=0.362$, respectively) (Table 1 ). However adults population exhibited significant positive correlation only with sunshine hours $(r=0.332)$. The role of relative humidity in population build up of this pest has also been reported by Sidhu and Batra, 1992; Batra et al., 2000; Sharma and Batra, 2001 and Zeb et al., 2011. Koli et al. (1981) noticed that the onset of mild humid climate in the state of Maharashtra favoured the population build up of this pest. Kumar (2001) also found relative humidity around $60-75 \%$ as conducive for development of this pest. The other parameters namely temperature (Tmax and Tmin.), rain-

Table 1. Correlation of $D$. citri population with weather parameters on citrus.

\begin{tabular}{lcc}
\hline \multicolumn{1}{c}{ Weather parameter } & Nymph & Adult \\
\hline Temperature (maximum) & -0.249 & -0.164 \\
Temperature (minimum) & -0.129 & 0.024 \\
Relative humidity (\%) Morning & $0.329^{*}$ & 0.269 \\
Relative humidity (\%) Evening & 0.271 & 0.239 \\
Wind direction (Morning) & 0.010 & -0.029 \\
Wind direction (Evening) & -0.017 & 0.128 \\
Sun shine hours & $0.362^{*}$ & $0.332^{*}$ \\
Rainfall (mm) & 0.071 & 0.198 \\
\hline
\end{tabular}

*Significant at $\mathrm{P}=0.05$ 
Table 2. Multiple regression analysis between $D$. citri population and abiotic factors on citrus.

\begin{tabular}{clc}
\hline \multicolumn{1}{c}{ Rymph } & \multicolumn{1}{c}{ R1 $1=-205.61+6.28 \mathrm{X} 1-5.45 \mathrm{X} 2-0.56 \mathrm{X} 3+2.97 \mathrm{X} 4-1.77 \mathrm{X} 5+1.84 \mathrm{X} 6+13.80 \mathrm{X} 7-1.87 \mathrm{X} 8$} & 0.45 \\
& $\mathrm{Y} 2=-64.22+12.44 \mathrm{X} 7+1.23 \mathrm{X} 4$ & 0.37 \\
\multirow{3}{*}{ Adult } & $\mathrm{Y} 3=-45.76-0.89 \mathrm{X} 1+1.37 \mathrm{X} 2-0.02 \mathrm{X} 3+0.62 \mathrm{X} 4-1.61 \mathrm{X} 5+1.86 \mathrm{X} 6+8.65 \mathrm{X} 7-0.05 \mathrm{X} 8$ & 0.45 \\
& $\mathrm{Y} 4=-32.87+6.73 \mathrm{X} 7+0.66 \mathrm{X} 4$ & 0.30 \\
\hline
\end{tabular}

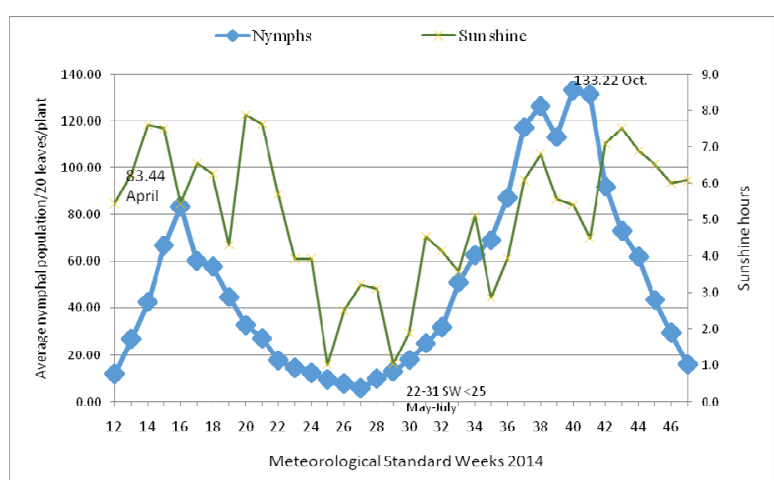

Fig. 1. Population of D. citri nymphs in relation to sunshine hours during different standard weeks on citrus.



Fig. 3. Population of D. citri nymphs in relation to other environmental variables during different standard weeks on citrus.

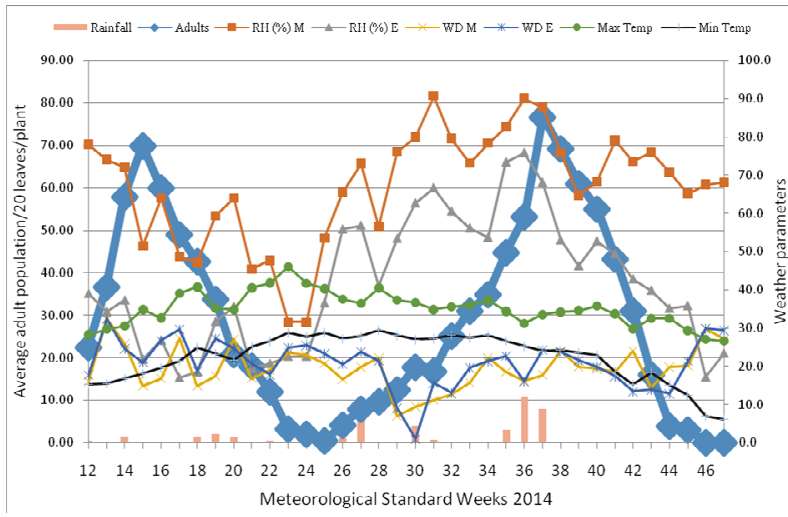

Fig.5. Population of D. citri adults in relation to other environmental factors during different standard weeks on citrus.

fall (RF) and wind direction (WD) were found to have no significant correlation with $D$. Citri nymphal and

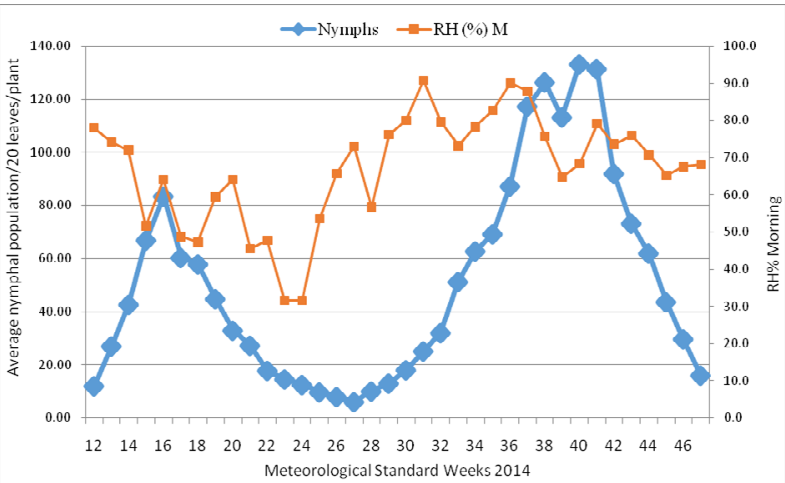

Fig. 2. Population of D. citri nymphs in relation to morning relative humidity during different standard weeks on citrus.

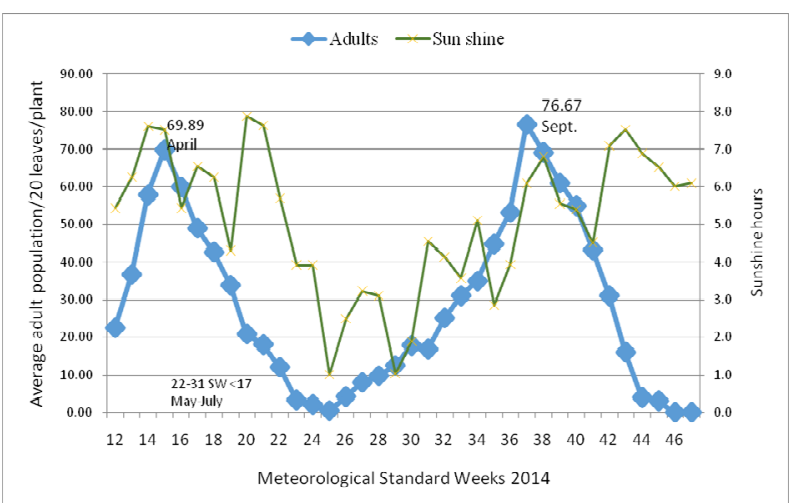

Fig.4. Population of D. citri adults in relation to sunshine hours during different standard weeks on citrus.

adult population. The multiple regression analysis as statistical tool to analyze the amount of changes in $D$. citri population per unit change in weather parameters revealed significant contribution of weather phenomenon in the variability of adult as well as nymphal population (Table 2). Out of $45 \%$ variability in whitefly nymphal population due to various abiotic factors, evening relative humidity (RHe) and sunshine hours (SS) accounted for 37\% variability (regression equation - Y2). Among these two factors, 24 per cent variation in nymphal population was due to evening relative humidity while 13 per cent was due to sunshine hours. Regarding adult population, evening relative humidity (RHe) and sunshine hours (SS) accounted for $30 \%$ variability (regression equation - Y4). Out of the total variability of 30 per cent variation in adult population, 20 per cent was due to evening relative humidity, while 10 per cent attributed to sunshine hours. The 
nymphal population had negative correlation with mean minimum and maximum temperature, while the adult population showed negative correlation with mean maximum temperature. Kumar (2001) also calculated multiple regression analysis between $D$. citri population and weather parameters and reported that out of all weather parameters sunshine hours (SS) and temperature mainly account for variability in the pest population.

Impact of the study: This study generated valuable data on the population dynamics of this pest which is polyphagus in nature and proving a menace to number of crops. The data so generated would help in the forecast about it likely incidence on the basis of prevailing weather and shall also prove helpful in devising a coherent strategy for its management.

\section{Conclusion}

The information on population dynamics of any insect pest in a given ecological niche should be considered as starting point for evolving eco- friendly pest management package. It is an established fact that population dynamics of any insect is greatly influenced by weather fluctuations and thereby the location specific studies become more imperative. Although study of population dynamics of this study were conducted elsewhere but this is first study of its kind in the state of Haryana. The population dynamics revealed by this study has far reaching significance in pest management strategy as integrated control measures may be focused only during the period wherein population exceeds economic threshold level (ETL).

\section{REFERENCES}

Anonymous. (2013). Statistical Abstract of Haryana 20112012. Published by Department of Economic and Statistical Analysis, Haryana 2013. pp. 130-258.

Argov, Y., Rossler, Y., Voet, H. and Rosen, D. (1999). The biology and phenology of the citrus whitefly, Dialeurodes citri, on citrus in the Coastal Plain of Israel. Entomologia Experimentalis et Applicata,93 : 21-27.

Batra, R.C., Sharma, D.R. and Arora, P.K. (2000). Current status of citrus pest: Hitech citrus management, Proc. International Symposium on citriculture at Nagpur (Nov. 23-27) pp. 938-944.

Dhiman, J.S. and Batra, R.C. (1998). Eco-friendly approaches foe management of disease and pests in fruit crops. International conference on Pest and Pesticide management for Sustainable Agriculture held at C.S.A.U.A. \& T., Kanpur, India (11-13 December, 1999) pp. 35-37.

Dhiman, J.S. and Batra, R.C. and Sharma, D.R. (2000). Synchronous attack of insect pests and diseases in kinnow; Hitech citrus management, Proc. International Symposium on citriculture at Nagpur (Nov. 23-27) pp. 810-817.

Koli, S.Z., Maker, P.V. and Choudhari, K.G. (1981). Seasonal abundance of citrus pests and their control. Indian Journal of Entomology,43 (2) 183-187.

Kumar, R. (2001). Management of citrus whitefly, Dialeurodes citri Ashmead. M.Sc.(Agric.) Thesis. Punjab Agricultural University, Ludhiana, Punjab.

Sharma, D.R. and Batra, R.C. (2001). Impact of different environmental factors on build up of population on citrus pest, Souveniar National Symposium on plant protection Strategies for Sustainable Agriculture held at S.K.U.A.S.T. Jammu (October 12-13, 2001) pp. 71-72.

Sidhu, D.S. and Batra, R.C. (1992). Influence of abiotic fac- 